\title{
Factors Associated with consistent condom use among internally displaced women in Leogane, Haiti: Results from a cross- sectional tablet-based survey
}

\author{
Logie, CH, Daniel, CA, Wang, Y.
}

Version Post-Print

Citation Logie, CH, Daniel, CA, \& Wang, Y. Correlates of consistent condom

(published version) use among internally displaced women in Leogane, Haiti: Results from a cross-sectional tablet-based survey. BMJ Sexually Transmitted Infections Published Online First: [March 31, 2016]. doi: 10.

1136/sextrans-2015-052400

Copyright / License Publisher retains copyright.

Publisher's Statement This is the post-print version of the published article, founds here: http://sti.bmj.com/content/early/2016/03/31/sextrans-2015-

052400. full.pdf + html?sid=4391 aa1a-6e99-4997-9dc0-e164a100da88

\section{How to cite TSpace items}

Always cite the published version, so the author(s) will receive recognition through services that track citation counts, e.g. Scopus. If you need to cite the page number of the TSpace version (original manuscript or accepted manuscript) because you cannot access the published version, then cite the TSpace version in addition to the published version using the permanent URI (handle) found on the record page. 
Original Article

Factors associated with consistent condom use among internally displaced women in Leogane, Haiti: Results from a cross-sectional tablet-based survey

Carmen Logie, ${ }^{1,2}$ CarolAnn Daniel $^{3}$, Ying Wang ${ }^{1}$

1 Factor-Inwentash Faculty of Social Work, University of Toronto, Toronto, Canada

2 Women's College Research Institute, Women's College Hospital, University of Toronto, Toronto, Canada

3 Faculty of Social Work, Adelphi University, Garden City, New York, United States

Keywords: condom; STI and HIV prevention; Haiti; women; poverty; violence

\section{Key messages:}

There is a need to better understand factors associated with consistent condom use among internally displaced women in post-disaster contexts, such as Haiti

$>$ Intrapersonal (e.g. depression), interpersonal (e.g. lower relationship power), and structural (e.g. food insecurity) level factors reduced likelihood of condom use

$>$ Interventions to increase condom use among internally displaced women should be tailored for women's relationship contexts and women involved in sex work 


\begin{abstract}
Objectives: Scant research has examined factors associated with condom use among internally displaced women in post-disaster settings, such as in post-earthquake Haiti. The study objective was to examine social ecological factors associated with consistent condom use among internally displaced women in post-earthquake Haiti.
\end{abstract}

Methods: A cross-sectional survey was conducted in 2012 with a peer-driven recruitment sample of internally displaced women in Leogane, Haiti. Peer health workers administered tablet-based structured interviews to a convenience sample of 175 internally displaced women.

Results: The 128 participants who reported being sexually active in the past four weeks were included in analyses. Two-thirds (65.2\%) reported consistent condom use in the past month. In multivariate logistic regression analyses controlled for age and income, participants that reported sex work, depression, higher number of sex partners, and shorter relationship duration had lower odds of consistent condom use in the past month. Participants that reported no experiences of intimate partner violence, lower self-rated health, higher sexual relationship power, and more meals per day, had a higher likelihood of reporting consistent condom use.

Conclusions: This research provides the first assessment of contextual factors associated with consistent condom use among women displaced from a natural disaster such as Haiti's 2010 earthquake. Findings demonstrate the importance of social ecological approaches to understand intrapersonal (e.g. sex work, depression), interpersonal (e.g. relationship power, 
intimate partner violence, relationship duration) and structural (e.g. food insecurity) factors associated with internally displaced women's condom use. Results can inform future sexual health research and interventions in international disaster contexts. 


\section{INTRODUCTION}

Annually an average of 26.4 million people have been displaced from their homes due to natural disasters since 2008[1]. Protracted displacement, where persons are displaced for over 1 year with limited progress or durable solutions, impacts over 700,000 persons in 34 global settings. The confluence of poverty, increased gender-based violence, and limited access to sexual health services elevate HIV infection risks among women displaced from disasters and conflict[2,3]. There is an urgent need for data on sexual health and HIV vulnerabilities among internally displaced women to inform policy and practice in international crises from natural disasters[1]

Haiti's 2010 earthquake resulted in over 200,000 deaths and the displacement and homelessness of 2 million people[3]. In 2015 almost 65,000 people continued to experience protracted displacement in Haiti where they face chronic vulnerability to poverty, overcrowding, and unsafe living conditions[1]. Haiti has the highest number of people living with HIV, new HIV infections, and AIDS deaths in the Caribbean, and the second highest HIV prevalence $(2.1 \%)$ in the region after the Bahamas[4]. Of Haiti's 130,000 people living with HIV, an estimated 78,000 (60\%) are women[4]. Young women aged 15-24 have higher HIV infection rates $(0.9 \%)$ than young men $(0.6 \%)$ [4]. This overrepresentation of women in Haiti's HIV epidemic underscore the salience of understanding HIV prevention uptake among internally displaced women in post-earthquake Haiti.

Young women in Haiti had elevated HIV vulnerability even before the 2010 earthquake, with lower knowledge of AIDS than young men (33.9\% vs. 40.1\%)[4] and STI rates almost 
twice as high[5] as young men. A 2013 UNAIDS study reported that among women in Haiti who had more than one sex partner in the past 12 months, less than half (43.2\%) used a condom during their last sexual encounter[4]. These results are similar to the other Caribbean country involved in the same study, the Dominican Republic, that reported women's condom use rates of $34.9 \%$ in the past 12 months[4]. Few studies have explored factors associated with internally displaced women's uptake of HIV prevention, such as condom use, in post-earthquake Haiti. Severe et al.’s (2014) qualitative study with young women (aged 18-24) in post-earthquake Port-au-Prince reported barriers to condom use among young women included inequitable power dynamics (e.g. male partners not wanting to use condoms) as well as misconceptions about condoms[6].

Our study objective was to understand socio-demographic, structural, interpersonal, and intrapersonal factors associated with consistent condom use among internally displaced women in Leogane, Haiti.

\section{METHODS}

\section{Study Design}

This study was implemented from January to May 2012 in Leogane, Haiti, the epicenter of the 2010 earthquake. Leogane has a population of approximately 122,000; $80 \%$ of the buildings were destroyed in the 2010 earthquake and 20,000 to 30,000 of its approximately 120,000 population died during the earthquake[7]. There was limited access to adequate 
health care services in Leogane before and following the earthquake[8]. Participants were recruited using modified peer driven recruitment strategy, an approach used to engage people who experience marginalization and may be hard to reach $[9,10]$. The research was designed and conducted in collaboration with NEGES Foundation, a community-based agency in Leogane, who purposively sampled, trained and hired internally displaced women $(n=8)$ as peer health workers (PHW). To reduce bias we hired PHW who reflected diversity in age, residence and socio-economic status, and also limited the number of participants PHW could recruit each from their social networks to 25[9]. PHW recruited participants from social networks, and used word-of-mouth and snowball sampling techniques to recruit a maximum of 25 participants each. No print materials were used to recruit participants due to low levels of literacy, and all recruitment and study activities were conducted in Kreyol, the local dialect.

We aimed to recruit 200 people; a sample size of 148 was calculated as sufficient for logistic regression analyses using $\mathrm{G}^{*}$ Power software (OR 2.0, $\mathrm{p}<0.05$, power 0.95 ). To improve clarity and appropriateness of study measures for the local context we pilot-tested the survey with the 8 PHWs and the survey was translated into Kreyol, and back-translated into English. An honorarium of \$5 U.S. was provided to study participants. Research Ethics Board approval (2011-0033-E) was obtained from Women's College Hospital, University of Toronto, Toronto, Canada. This was a community-based collaboration with NEGES Foundation in Leogane, who provided guidance and feedback into the study design, research ethics protocol, and study implementation. 


\section{Participants and eligibility}

Inclusion criteria for study participants included persons who self-identified as women, aged 18 years and older, internally displaced (living in a tent, camp, and/or different residence due to dislocation from the 2010 earthquake), residing in Leogane or surrounding areas, and were able to provide informed consent.

\section{Survey measures}

We assessed consistent condom use with two questions: (1) number of times the participant had sex in the past 4 weeks and (2) number of times the participant used condoms when having sex in the past 4 weeks. If the participant reported the same number for both questions they were coded as practicing consistent condom use $(Y e s=1)$. If the participants reported using condoms less than the number of times they reporting having sex, they were coded as practicing inconsistent condom use $(\mathrm{No}=0)$.

We examined socio-demographic variables including age, monthly income (reported in US dollars), education (partial primary, primary and secondary and higher), employment, and sex work involvement in past 3 months (having sex in exchange for money, food, school fees, clothes, family items or transportation). To assess food security we asked for the number of daily meals typically consumed by participants.

We also examined relationship factors, including relationship status and relationship duration. To screen for intimate partner violence (IPV) we asked: "Have you ever 
experienced physical violence from your partner?", which was measured on a dichotomous scale (Yes=1, N=0) Sexual relationship power was measured using the 'relationship control' sub-scale from the Sexual Relationship Power Scale[18] (Cronbach's $\alpha=0.88$, sub-scale range $0-58)$.

We used the two-item Patient Health Questionnaire-2 (PHQ-2) to screen for depression symptoms over the past 2 weeks [19] (Cronbach's $\alpha=0.63$, scale range $0-8)$. Higher score of PHQ-2 means higher level of depression. To assess self-rated health (SRH) we used a single-item ("How would you rate your overall health?”). We assessed number of participants' sexual partners in the past year, and if participants had concurrent sexual partnerships in the past three months.

\section{Statistical analyses}

We conducted descriptive analyses of socio-demographic variables (e.g. age, income) to determine frequencies, means and standard deviations for each variable. We summed scale items. Categorical variables were re-coded as dichotomous dummy variables. We conducted multivariate logistic regression to determine the appropriate estimates of the adjusted risk ratio for consistent condom use, controlling for significant socio-demographic variables. We first conducted univariate modeling; socio-demographic variables significant at the $\mathrm{p}<0.05$ level were included in multivariate analysis. Non-missing participant responses were included in analyses. Statistical analyses were performed using STATA (version 12.0). 


\section{RESULTS}

\section{Study population}

There were 175 women who participated in this study; in the analyses we include the 128 participants who reported having had sex in the past four weeks. Table 1 describes the characteristics of the study participants $(n=128)$. The mean age was $36.6($ S.D. $=13.66)$. Nearly ten percent $(9.38 \%)$ of the participants reported exchanging sex for money, food and etc. Three quarters of participants reported receiving no monthly income. Three quarters (74.22\%) of participants consumed one meal or less per day. Almost half of the sample $(47.66 \%)$ rated their overall health as poor. We conducted bivariate analyses (t-test, Chi square and ANOVA) to assess differences in socio-demographic and outcome variables between participants who were included and excluded in analyses; we found no significant differences.

Table 1 Main characteristics of participants $(n=175)$

\begin{tabular}{lllll}
\hline Variables & Mean (SD) & $\begin{array}{l}\text { No. of participants } \\
\text { included }(\%)^{*} \\
(\mathrm{n}=128)\end{array}$ & $\begin{array}{l}\text { No. of } \\
\text { participants } \\
\text { excluded } \\
(\%)(\mathrm{n}=47)\end{array}$ & \\
& & & 36.50 & 0.933 \\
Age & $36.55(13.66)$ & 128 & $(13.55)$ & \\
& median=33 (range & & median=33 & \\
& $18-74)$ & & $(18-74)$ & \\
& & & $3.68(8.65)$ & 0.331 \\
& & & median= &
\end{tabular}


-43.09)

\begin{tabular}{|c|c|c|c|c|}
\hline \multirow[b]{2}{*}{$\begin{array}{l}\text { Sex work } \\
\text { involvement }\end{array}$} & \multirow[b]{2}{*}{ Yes } & \multicolumn{3}{|c|}{$0-34.47)$} \\
\hline & & $12(9.38)$ & $6(12.77)$ & 0.513 \\
\hline \multirow[t]{4}{*}{ Education } & Partial primary & $40(31.25)$ & $18(38.30)$ & 0.541 \\
\hline & Primary & $39(30.47)$ & $15(31.91)$ & \\
\hline & Secondary and & $49(38.28)$ & $14(29.79)$ & \\
\hline & higher & & & \\
\hline \multirow[t]{3}{*}{ Employment } & Not employed & $115(89.84)$ & $44(93.62)$ & 0.610 \\
\hline & $\begin{array}{l}\text { Full time job with } \\
\text { salary }\end{array}$ & $11(8.59)$ & $2(4.26)$ & \\
\hline & Unpaid work & $2(1.56)$ & $1(2.13)$ & \\
\hline \multirow[t]{4}{*}{ Meals per day } & 0 & $16(12.50)$ & $6(12.77)$ & 0.534 \\
\hline & 1 & $79(61.72)$ & $33(79.21)$ & \\
\hline & 2 & $29(22.66)$ & $18(38.30)$ & \\
\hline & $3+$ & $4(3.12)$ & $0(0)$ & \\
\hline \multirow[t]{4}{*}{ Relationship status } & Married & $6(4.69)$ & $8(17.02)$ & 0.051 \\
\hline & Living together & $103(80.47)$ & $32(68.09)$ & \\
\hline & $\begin{array}{l}\text { Dating-not living } \\
\text { together }\end{array}$ & $16(12.50)$ & $5(10.64)$ & \\
\hline & Casual dating & $3(2.34)$ & $2(4.26)$ & \\
\hline \multirow{4}{*}{$\begin{array}{l}\text { Relationship } \\
\text { duration }\end{array}$} & Less than 2 year & $36(28.12)$ & $22(46.80)$ & 0.362 \\
\hline & $2-5$ years & $24(18.75)$ & $12(25.53)$ & \\
\hline & 5-10 years & $25(19.53)$ & $14(29.79)$ & \\
\hline & 10 or more years & $43(33.59)$ & $12(25.53)$ & \\
\hline \multirow{3}{*}{$\begin{array}{l}\text { Self-rated overall } \\
\text { health }\end{array}$} & Good & $53(41.41)$ & $20(42.55)$ & 0.699 \\
\hline & Fair & $14(10.94)$ & $6(12.77)$ & \\
\hline & Poor & $61(47.66)$ & $21(44.68)$ & \\
\hline \multirow{3}{*}{$\begin{array}{l}\text { Number of sexual } \\
\text { partner }\end{array}$} & $3.99(1.98)$ & $124($ missing $=4)$ & - & 0.291 \\
\hline & median=4 (range & & & \\
\hline & $1-7)$ & & & \\
\hline Ever experienced & Yes & $41(23.84)$ & $8(18.18)$ & 0.307 \\
\hline
\end{tabular}


physical violence

from partner

Consistent condom Yes

$84(65.62)$

use

*Percentages calculated from non-missing responses for each variable.

\section{Associations with consistent condom use}

Logistic regression results are displayed in Table 2. This model explained $48.7 \%$ of the variation in consistent condom use scores (Pseudo $\mathrm{R}^{2}=0.487$ ). Univariate logistic regression results indicate that participants who were older and received any monthly income were more likely to report consistent condom use than those that were younger and received no monthly income. These were the only socio-demographic characteristics significantly associated with consistent condom use.

Multivariate logistic regression analyses controlling for age and income revealed that structural (meals per day), interpersonal (relationship duration, experienced intimate partner violence [IPV], sexual relationship power), and intrapersonal (sex work, depression, self-rated health, number of sexual partners in last year) factors were significantly associated with consistent condom use.

As illustrated in Figure 1, with a one unit increase in number of meals per day (structural factor) the likelihood of using condoms increased by $102 \%$.

Sexual relationship power, relationship duration, and IPV were interpersonal factors associated with consistent condom use. Figure 2 demonstrates the likelihood of consistent condom use for different sexual relationship power scores: with a one unit increase in sexual 
relationship power score, the likelihood of consistently using condoms increased by $12 \%$. Participants in a relationship for 2-5 years were over 5 times less likely to consistently use condoms than those in relationships for less a year. Participants who never experienced IPV were 2.8 times more likely to report consistent condom use than those who had experienced IPV.

Intrapersonal factors were also significantly associated with consistent condom use. With a one unit increase in depression symptom scores, the likelihood of consistently using condoms decreased by $38 \%$. Participants who rated their overall health as fair were 19 times more likely, and those who rated their health as poor were over 3 times more likely, to consistently use condoms than those who rated their health as good. With a one unit increase in the number of sexual partners, the likelihood of consistently using condoms decreased by 44\%. Participants who engaged in sex work were over 11 times less likely to consistently use condoms. Engaging in concurrent sexual partnerships was not significantly associated with consistent condom use.

Table 2 Univariate and multivariate logistic modeling of factors associated with consistent condom use $(n=128)$

\begin{tabular}{|c|c|c|c|c|}
\hline Variables & $\begin{array}{l}\text { Unadjusted logistic } \\
\text { regression analyses, OR } \\
(95 \% \mathrm{CI})\end{array}$ & p Value & $\begin{array}{l}\text { Adjusted logistic } \\
\text { regression analyses,* } \\
\text { OR }(95 \% \mathrm{CI})\end{array}$ & $\mathrm{p}$ Value \\
\hline
\end{tabular}

Socio-demographic variables

$\begin{array}{lll}\text { Age } & 1.04(1.02,1.08) & 0.003 \\ \text { Received monthly income } & 3.90(1.38,10.99) & 0.010\end{array}$


Education

Partial primary (ref) 1

$\begin{array}{lll}\text { Primary } & 0.77(0.30,1.96) & 0.577 \\ \text { Secondary and higher } & 0.74(0.30,1.80) & 0.504\end{array}$

Intrapersonal factors

$\begin{array}{lllll}\text { Sex work involvement in } & 0.08(0.01,0.40) & 0.002 & 0.09(0.01,0.47) & 0.004\end{array}$

past three months

Self-rated health

$1.53(1.03,2.27)$

$0.035 \quad 1.86(1.06,3.27)$

0.031

Depression

$0.68(0.55,0.85)$

$0.001 \quad 0.62(0.47,0.81)$

0.000

Number of sex partners

$0.61(0.49,0.77)$

0.000

$0.56(0.43,0.73)$

0.000

in past year

Concurrent sex partners in

$2.99(0.89,10.04)$

0.077

$2.65(0.74,9.52)$

0.135

past three months

Interpersonal Factors

No experiences of physical $3.80(1.66,8.69)$

0.002

$2.82(1.16,6.84)$

0.022

violence from partner

Sexual relationship power $1.14(1.05,1.24)$

0.001

$1.12(1.03,1.22)$

0.006

Relationship duration

Less than 2 year (ref) 1

$\begin{array}{lllll}\text { 2-5 years } & 0.19(0.06,0.59) & 0.004 & 0.18(0.05,0.58) & 0.004 \\ \text { 5-10 years } & 0.68(0.23,2.04) & 0.496 & 0.45(0.14,1.49) & 0.192 \\ 10 \text { or more years } & 1.45(0.52,4.09) & 0.479 & 0.67(0.21,2.18) & 0.507\end{array}$

Structural factors

Meals per day

$1.52(0.88,2.64)$

0.133

$2.02(1.11,3.71)$

0.022

Note: $85.48 \%$ correct classification of cases; Pseudo $\mathrm{R}^{2}=0.487$; Adjusted for age and received monthly income

\section{DISCUSSION}

Our study is among the first to explore intrapersonal, interpersonal and structural factors associated with consistent condom use among internally displaced women in any global natural disaster context. The model is statistically significant and explained nearly half of the 
variation (Pseudo $\mathrm{R}^{2}=0.487$ ) in consistent condom use. Our study identifies a set of social ecological[11] factors associated with consistent condom use among internally displaced women in post-earthquake Leogane, Haiti.

Our finding that two-thirds of women consistently used condoms is similar to Severe et al.'s (2014) study in which $60 \%$ of young Haitian women used condoms. This is higher than the UNAIDS 2013 report that found $43.2 \%$ of women in Haiti aged 15-49 with multiple sexual partners in the past 12 months used a condom at last sex[6]. This could be due to our non-random sample, and/or the different sample characteristics (i.e. we included women who did and did not have multiple partners) and measures (i.e. condom use every time in past 4 weeks vs. at last sexual encounter). Our finding that participants in a relationship for longer were less likely to consistently use condoms corroborates prior research[12, 13]. Complex interpersonal relationships dynamics may change over time and reduce risk perceptions and increase feelings of emotional closeness and relationship importance-contributing to reduced condom use[12, 13].

Similar to prior research we found that consistent condom use among women was lower among those who had experienced IPV in their relationship[14, 15], and higher among women who reported greater relationship power[6, 15, 16]. Gender power inequities and IPV are structural pathways to women's HIV risk: they reduce women's ability to request male partners to use condoms[17]. Our finding that almost $24 \%$ of participants ever experienced IPV is higher than prior reports in which $16 \%$ of women reported having experienced IPV from a male intimate partner in the past 12 months[4]. This could be due to our question 
asking if they ever experienced IPV by their current partner rather than limiting it to the past year.

We found food security was associated with increased condom use, this corroborates prior research in Sub-Saharan Africa that demonstrates associations between food insecurity and inconsistent condom use[14,18]. Women living in poverty may be dependent on others for food while simultaneously needing to support children and other family members, and this economic dependency may limit their ability to negotiate safer sex practices[6, 17, 18]. Understanding linkages between food security and condom use is particularly important in Haiti where over half $(53.4 \%) — 5.8$ million people — of the population is undernourished[19].

Intrapersonal factors were also associated with consistent condom use. Participants who reported depressive symptoms were less likely to use condoms, corroborating prior studies that report associations between depression and reduced condom use among women[20-22]. Depression may be associated with maladaptive coping strategies, that could include sex as a coping mechanism for negative feelings; alternatively, persons experiencing depression may demonstrate avoidant coping that may compromise condom negotiation[20, 22]. Participants who rated their health as fair/poor were more likely to report consistent condom use than those rating their health as good; this could be attributed to those with good health viewing themselves at lower risk for HIV.

There were several study limitations. Our non-random sample limits generalizability of findings. The cross-sectional design precludes in-depth understanding of causality and factors associated with consistent condom use changes over time. We only had one measure of IPV 
that explored physical violence; a more nuanced assessment could have provided insight into types of IPV. Social desirability bias may have led to participants over-reporting consistent condom use.

Despite these limitations, to our knowledge this is one of the first studies to apply a social ecological approach to understanding contexts of consistent condom use among internally displaced women. Future studies should engage more representative samples of internally displaced women and apply longitudinal methods to understand the trajectory of HIV vulnerabilities in post-disaster settings. Research could use larger samples to allow exploration of HIV vulnerabilities among sub-groups of internally displaced women, such as women engaged in sex work. Additionally, future studies and interventions could examine when women desire condom use as well as other forms of protective partnerships, rather than positing condom use as universally desirable.

The Internal Displacement Monitoring Centre (IDMC)'s recommendations for interventions with internally displaced persons reported the need to address: social and psychological consequences of displacement[2], such as depression; income generation; and healthcare access. The IDMC highlights the need to tailor approaches for context, class, gender and age; our findings also point to the need for interventions tailored for relationship contexts and sex work involvement. UNHCR and the Human Rights Centre at Berkeley Law's report highlighted the need for shelters in Haiti for survivors of GBV that provided housing and addressed emotional wellbeing (e.g., informal group counseling)[23]. The Inter-Agency Standing Committee (IASC) Task Force on HIV recommends HIV prevention 
in humanitarian settings include participatory life-skills HIV education that addresses risk reduction, sex work and GBV, and integration of HIV education and prevention into shelter activities, including food distribution and community centres[24]. Taken together, recommended sexual health promotion strategies in disaster and humanitarian settings address social ecological factors identified as important to condom use uptake in our study, including GBV and food security.

Condoms are a key component of a comprehensive HIV prevention strategy, and increased condom use has effectively reduced HIV incidence in other contexts, such as Southern Africa[25]. Strategies aiming to reduce HIV and STI vulnerabilities among internally displaced women in Haiti require approaches that address individual, relational and structural vulnerabilities[6, 25].

Contributors CL and CD conceptualized the study design and conducted data collection. CL led the writing and development of this manuscript. YW conducted data analysis.

Funding This work was supported by a Grand Challenges Canada Rising Star in Global Health Award [grant number 0016-01-04-01-01] and a Canadian Institutes of Health Research Planning Grant [grant number 2011-255165].

Ethics approval Women's College Research Institute, Women's College Hospital at the University of Toronto, Canada (WCH REB \#: 2011-0033-E).

\section{Competing Interests None}




\section{REFERENCES}

1. Internal Displacement Monitoring Centre. Global Estimates 2015: People displaced by Disasters. Geneva: 2015. Available from:

http://www.internal-displacement.org/assets/library/Media/201507-globalEstimates-2 015/20150713-global-estimates-2015-en-v1.pdf

2. MADRE. One Year Updated Our Bodies Are Still Trembling: Haitian Women Continue to Fight Against Rape. New York: MADRE; 2011. Available from: http://www.madre.org/uploads/misc/1283377138_2010.07.26\%20-\%20HAITI\%20GB V\%20REPORT\%20FINAL.pdf.

3. UNAIDS. Progress in Restoring Access to HIV Services in Haiti. Geneva: 2011. Available from http://www.unaids.org/en/resources/presscentre/featurestories/2011/january /20110112haiti.

4. UNAIDS. Global report: UNAIDS report on the global AIDS epidemic 2013. 2013. Available from http://www.unaids.org/sites/default/files/media_asset/UNAIDS_Global_Report_2013 _en_1.pdf.

5. Dorjgochoo T, Noel F, Deschamps MM, et al. Risk factors for HIV infection among Haitian adolescents and young adults seeking counseling and testing in Port-au-Prince. JAIDS 2009; 52(4): 498-508.

6. Severe L, Fitzgerald DW, Deschamps MM, et al. "I Am Proud of Mself, Just the Way I Am” (Mwen Fyé De Tét Mwen, Jan Mwen Ye Ya): A Qualitative Study Among Young Haitian Women Seeking Care for Sexually Transmitted Infections (STIs) in Haiti. AIDS education and prevention: official publication of the International Society for AIDS Education 2014;26(2)158.

7. Julmy S. Coordinating the earthquake response: lessons learned from Leogane, western Haiti. Humanitarian Exchange Magazine 2011. Available:

http://odihpn.org/magazine/coordinating-the-earthquake-response-lessons-from-leoga ne-western-haiti/

8. Urrutia RP, Merisier D, Small M, et al. Unmet health needs identified by Haitian women as priorities for attention: a qualitative study. Reproductive health matters 2012; 20(39): 93-103. Available from http://www.ncbi.nlm.nih.gov/pmc/articles/PMC3697112

9. Magnani R, Sabin K, Saidel T, et al. Review of sampling hard- to -reach and hidden populations for HIV surveillance. AIDS 2005;19:S67-72.

10. Tiffany JS. Respondent-driven sampling in participatory research contexts: participant 
driven recruitment. Journal of Urban Health 2006;83:113-23.

11. Baral S, Logie C, Grosso A, et al. Modified social ecological model: a tool to visually represent the risks and risk contexts of HIV epidemics. BMC Public Health $2013 ; 13: 482$.

12. Manning W, Flanigan M, Giordano C, et al. Relationship dynamics and consistency of condom use among adolescents. Perspectives on sexual and reproductive health 2009;41(3):181-190.

13. Katz BP, Fortenberry JD, Zimet DG, et al. Partner- specific relationship characteristics and condom use among young people with sexually transmitted diseases. Journal of Sex Research 2000; 37(1):69-75.

14. Dunkle KL, Jewkes RK, Brown HC, et al. Gender-based violence, relationship power, and risk of HIV infection in women attending antenatal clinics in South Africa. The Lancet 2004; 363:1415-1421.

15. Kacanek D, Bostrom A, Montgomery ET, et al. Intimate Partner Violence and Condom and Diaphragm Nonadherence Among Women in an HIV Prevention Trial in Southern Africa. Journal of Acquired Immunodeficiency Syndrome 2013;64(4):400-8

16. Pulerwitz J, Gortmaker SL, DeJong W. Measuring sexual relationship power in HIV/STD research. Sex Roles 2002;42:637-660.

17. Krishnan S, Dunbara SM, Minnisa MA, et al. Poverty, Gender Inequities, and Women's Risk of Human Immunodeficiency Virus/AIDS. Annals of the New York Academy of Science 2008;1136(1):101-10.

18. Weiser SD, Leiter K, Bangsberg DR, et al. Food insufficiency is associated with high-risk sexual behavior among women in Botswana and Swaziland. PLoS Med 2007;4(10):1589-1597.

19. Food and Agriculture Organization of the United Nations [FAO]. The state of food insecurity in the world. Meeting the 2015 international hunger targets: Taking stock of uneven progress. Rome: FAO: 2015. Available from http://www.fao.org/3/a-i4646e.pdf

20. Walch SE, Rudolph SM. Negative affect and risk for human immunodeficiency virus: one size may not fit all. American Journal of Health Promotion 2006;20(5):324-333.

21. Islam N, Laugen C. Gender differences in depression and condom use among sexually active Canadians. Journal of affective disorders 2015;174:511-515.

22. Johnson LF, Hallet TB, Rehle TM, et al. The effect of changes in condom usage and antiretroviral treatment coverage on human immunodeficiency virus incidence in South Africa:a model-based analysis. Journal of the Royal Society Interface 2012;rsif20110826. 
23. Freccero J. Sheltering displaced persons from sexual and gender-based violence. Forced Migration Review 2015:50:55.

24. UNAIDS Inter-Agency Standing Committee (IASC). Guidelines for Addressing HIV in Humanitarian Settings. Geneva: UNAIDS Inter- Agency Standing Committee (IASC), 2010

25. Dworkin SL, Treves-Kagan S, Lippman SA. Gender-transformative interventions to reduce HIV risks and violence with heterosexually-active men: a review of the global evidence. AIDS and Behaviour 2013;17(9):2845-63. 
License Statement: The Corresponding Author has the right to grant on behalf of all authors and does grant on behalf of all authors, an exclusive licence (or non-exclusive for government employees) on a worldwide basis to the BMJ and co-owners or contracting owning societies (where published by the BMJ on their behalf), and its Licensees to permit this article (if accepted) to be published in Sexually Transmitted Infections and any other BMJ products and to exploit all subsidiary rights, as set out in our licence.

Competing Interest: None declared. 